\title{
Technical Efficiency Analysis of Fisheries: Toward an Optimal Fleet Capacity
}

\author{
Mansour Zibaei (Corresponding author) \\ Agricultural Economic Department, College of Agriculture, Shiraz University \\ PO code: 71441-65186, Shiraz, Iran \\ Tel: 98-711-228-6082Ｅ-mail: zibaei@shirazu.ac.ir
}

Received: October 14, 2011

Accepted: November 14, $2011 \quad$ Published: February 1, 2012

doi:10.5539/sar.v1n1p96

URL: http://dx.doi.org/10.5539/sar.v1n1p96

\begin{abstract}
Technical efficiency analysis has a vital role in fishing management and decommissioning programs. In this context, ignoring the variation across the regions in the field of natural endowment and technology may lead to biased estimates of efficiency scores. Therefore, efficiency analysis in the southern coastal provinces of Iran, which is the aim of this study, was investigated by a metafrontier production function that was the same for all studied provinces. The required data was obtained from a random sample of 520 fishery vessels. The results of the estimating metafrontier showed that mean technical efficiency for selected provinces varies between 0.408 and 0.542 , while ranging between 0.650 and 0.728 when assessed according to the regional frontier. The highest mean technical efficiency based on metafrontier is devoted to Sistan-va-Baluchestan, while Bushehr has the lowest mean technical efficiency. The results also indicated that the main explanations, beyond the fact that Sistan-va-Baluchestan has the highest technical operation in comparison with other provinces are access to more suitable vessels and especially, access to the deeper water in the Oman Sea and Indian Ocean to fish the big pelagic species.
\end{abstract}

Keywords: Technical efficiency, Metafrontier, Fishing management, Decommissioning program, Iran, Pelagic species

\section{Introduction}

Iran is the largest fishing nation in the region with a coastline of $2700 \mathrm{~km}$, of which $1800 \mathrm{~km}$ is in the Persian Gulf and the Oman Sea. Despite these potentials and a diversified climate suitable for various types of aquaculture systems in the land area, the fisheries sub sector contributed only $0.19 \%$ of the GDP in 2006 and catch from wild natural resources is limited due to resource misallocation, low efficiency, overexploitation of fish resources (especially shrimp, silver pomfret and demersal species) and illegal fishing (FAO, 2005). In order to improve matters and balance between fish landed and living marine resources, the major remedial measures suggested are: fish conservation and enhancement, deep sea fisheries development, improved aquaculture efficiency, the promotion of fishing management and a buy-back scheme for reducing fleets to an appropriate size given the available fishing opportunities (FAO, 2005). In this context, knowledge of the technical efficiency at fleet level and its determinant factors would be valuable information not only to attain the maximum output from a set of inputs or to produce an output using the lowest possible amount of inputs, but also for a decommissioning program (Idda et al., 2009; Lindebo et al., 2007; Maravelias \& Tsitsika, 2008). Actually, the success of a decommission program depends on the variation and the level of efficiency within the fishing fleets. The diminution in fleet capacity will be less than anticipated if fleets with lower than average efficiency levels are decommissioned. Furthermore, if the residual fleets get better their technical efficiency it may even further counterbalance the effects of the decommissioning program (Eggert, 2001; Lindebo et al., 2007). Due to the key role of technical efficiency and its determinant factors in fishing management and a decommissioning program, there is a growing interest in the measurement of technical efficiency and the factors determining it at fishing fleet level (Esmaeili, 2006; Garcia del Hoyo et al., 2004; Hjalmarsson et al., 1996; Huang \& Wang, 2002; Idda et al., 2009; Kirkley \& Squires, 1999; Kirkley et al., 2002; Lindebo et al., 2007; Maravelias \& Tsitsika, 2008; Pascoe et al., 2001; Reid et al., 2003; Reinhard et al., 2000; Squires et al., 2003; Tingley et al., 2005; Vestergaard et al., 2003). 
The fishery manager may decrease technical efficiency by restricting the use of certain inputs or alternatively, they may improve it by increasing these inputs or by taking measures that correctly define the property rights of the fisheries (Esmaeili, 2006; Hoyo et al., 2004; Maravelias \& Tsitsika, 2008). All of the aforementioned studies measure the technical efficiency of fleets inside the region according to the regional frontier production function. The regions differ from each other in geography, natural endowment and technology, therefore ignoring the variation across the regions may lead to biased estimates of efficiency scores, and hence misleading policy implications(Battese et al., 2004). However, for making efficiency comparisons across regions, which is the aim of this study, frontier for different regions must be the same. In this study, we perform this by measuring technical efficiency relative to a recently developed metafrontier production function(See: Battese et al., 2004). A metafrontier methodology is an overarching function that encompasses the frontier production functions operating under different technologies involved. Comparable efficiencies and technology gaps under different technologies relative to the potential technology available to the economy can be estimated by this model (Battese et al., 2004). The studied provinces or regions then may be ranked founded on their technical operation by technology gaps ratio (Battese et al., 2004).

\section{Method}

\subsection{Methodological Framework}

The essential approach for measuring fishery vessel level efficiency is to estimate a frontier production function that surrounds all the input-output data, any vessel that lies below the frontier curve is considered to be inefficient; this vessel could either decrease its input use at the same time as maintaining output or it could use the same amount of input and raise output. Those vessels lying on the frontier curve being explained as technically efficient. Differences in available stocks of physical, human and financial capital, technologies, and resource endowments have led efficiency investigators to estimate production frontiers for different regions and different groups of firms. After estimating a frontier production function for a region, it is simple to measure the technical efficiency of vessel inside the region (e.g., Hormozgan fishery vessels) according to the regional frontier production function. But, for making efficiency comparisons across regions (e.g., comparing efficiency levels of Hormozgan fishery vessels with efficiency levels of Sistan-va-Baluchestan fishery vessels), the frontier for different regions must be the same (O`Donnell et al., 2007). In this study, this is performed by measuring efficiency relative to a metafrontier production. Metafrontier production function can be estimated using data envelopment analysis (DEA) or stochastic frontier analysis (SFA) (Battese et al., 2004). There are several reasons for using DEA analysis to estimate technical efficiency. The main reasons are that DEA does not need a parametric specification of a function form to estimate the frontier production function, and it can also provide accommodation multiple outputs into analysis (Sharma \& Leung, 1998; Tingley et al., 2005). Apart from measuring efficiency, applications using DEA have been recommended by FAO (1998) to also measure fishing capacity (Garcia del Hoyo et al., 2004; Kirkley \& Squires, 1999; Kirkley et al., 2002; Pascoe et al., 2001; Reid et al., 2003; Vestergaard et al., 2003). A disadvantage of the DEA, however, is that it does not account for random variation in the output, and as a result attributes any visible deficit in output to technical efficiency (Tingley et al., 2005).

\subsection{Data Envelopment Analysis}

If region $\mathrm{k}$ consists of data $\mathrm{Qn} \underline{\mathrm{L}} \mathrm{K}$ vessels, a metafrontier production function can be estimated by the DEA to the inputs and outputs of all ${ }_{\mathrm{k}=1} \mathrm{k}_{\mathrm{k}}$ fishery vessels in all studied regions. The formation of metafrontier linear programming is as follows (O'Donnell et al., 2007):

$$
\begin{array}{ll}
\max _{\phi_{i}, \lambda_{i}} \phi_{i} & \\
\text { s.t. } & \phi_{i} y_{i}-Y^{\prime} \lambda_{i} \leq 0, \\
& X \lambda_{i}-x_{i} \leq 0, \\
& j^{\prime} \lambda_{i}=1 \\
& \lambda_{i} \geq 0,
\end{array}
$$

Where

yi is the catch amount of $\mathrm{i}$-th vessel;

$\mathrm{xi}$ is the $\mathrm{N} \times 1$ vector of input amounts for $\mathrm{i}$-th vessel;

$\mathrm{Y}$ is the $\mathrm{L} \times 1$ vector of catch amounts for all $\mathrm{L}$ vessels; 
$\mathrm{X}$ is the $\mathrm{N} \times \mathrm{L}$ matrix of input amounts for all $\mathrm{L}$ vessels;

$\mathrm{j}$ is an $\mathrm{L} \times 1$ vector of ones;

$\lambda$ is an $\mathrm{L} \times 1$ vector of weights; and $1 \leq \phi_{\mathrm{i}}<\infty$ is a scalar and $\phi_{\mathrm{i}}-1$ is the proportional increase in output that could be attained by $\mathrm{i}$-th fleet, with input use held constant. Thus, $\frac{1}{\phi_{i}}$ which takes values between 0 and 1 is an

estimate of the technical efficiency measure. To gain a set of $\mathrm{N}$ technical efficiency scores, the problem requires to be solved $\mathrm{N}$ times, one for each fleet. Actually, the tiresome work of solving a different linear programming (LP) for every fleet is usually undertaken using loop command in software packages such as GAMS (Brooke $e t$ al., 1998). The above model can be applied to form a convex province- $\mathrm{k}$ frontier by using the DEA model to the observed inputs and output of vessels in a province. Finally, having estimated the technical efficiencies of fishery fleets according to the metafrontier and province frontier, the technology gap ratio (TGR) for province-k fleets is computed as (Battese et al., 2004):

$$
\mathrm{TGR}^{\mathrm{k}}=\frac{\mathrm{TE}}{\mathrm{TE}^{\mathrm{k}}}
$$

Where, $\mathrm{TE}$ and $\mathrm{TE}^{\mathrm{k}}$ are the technical efficiency according to the metafrontier and province-k frontier, respectively. This ratio illustrates the maximum catch that could be obtained by a vessel from province $\mathrm{k}$ as a percent of the catch that is possible by the metatechnology. This ratio shows the technical operation and the studied provinces can be ranked founded on their technical operation by this ratio. Due to the flexibility that GAMS offers, the DEA model was written in this software. Modification GAMS code to account for changes to the standard DEA is easy and can use greater control over output formats. These features are imperative in fishery studies where efficiency analysis often differs from that available with the standard DEA model (Walden and Kirkley, 2000).

\subsection{Data}

Four coastal provinces of Iran have important fisheries on their side of the Persian Gulf and the Oman Sea. Total fish landing of these provinces have been, for the most part, stable in the period 1992-2001, but have increased since 2001 with exception of year 2006 (Figure 1). As shown in Table 1, Hormozgan is the largest province and about $37 \%$ of the total landed in 2006 on the Iranian southern fishery came from this province. But, Sistan-va-Baluchestan has the highest fish landing per fisherman. In this study a random sample of 520 wooden fishery vessels was selected using stratified random sampling method from Bushehr, Hormozgan and Sistan-va-Baluchestan. These provinces are the major fishery provinces and account for roughly 86 percent of total fish landed in 2006 on the Iranian side of the Persian Gulf and the Oman sea. Because the application of DEA needs vessels to keep their number of input and output variables at a reasonable level, five important input variables are considered as follows: $x 1$, the number of labor (the number of crew) employed in the $\mathrm{i}$-th vessel; $\mathrm{x} 2$, number of fishing days by the i-th vessel in the studied year; $\mathrm{x} 3$, the engine horsepower of the $\mathrm{i}$-th vessel; and $\mathrm{x} 4$, the number of nets (gear) used by the i-th vessel, and dependent variable or output variable is the catch quantity of i-th vessel.

\section{Results}

Estimated technical efficiencies according to the regional frontier production function and the metafrontier production function, together with estimated TGRs, are shown in Table 2. Based on Table 2, the average technical efficiency score for Hormozgan province is 0.728 ; demonstrating fish landed is raised by about $73 \%$ of the potential, given its regional frontier. In other words, the mean gap between the best fisherman and other fishermen is about $27 \%$ in this province. However, the mean technical efficiency of Hormozgan is 0.479 when evaluated according to the metafrontier production function. Thus, the technology gap ratio for Hormozgan is $0.665(0.479 / 0.728)$. This denotes that, given the input vector, the potential fish landed for this province is about $67 \%$ of that represented by the metatechnology. As designated in Table 2, mean technical efficiency estimate according to the regional frontier for Sistan-va-Baluchestan province is very close to the score reported for Hormozgan, while based on this frontier; Bushehr has the lowest mean technical efficiency. Average technical efficiency for the studied provinces ranges between 0.408 and 0.542 when assessed based on the metafrontier production function. The highest mean technical efficiency according to metafrontier is assigned to Sistan-va-Baluchestan, while Bushehr has the lowest mean technical efficiency. The value of the technology gap ratio for Sistan-va-Baluchestan and Bushehr is 0.763 and 0.641 respectively. Thus, DEA scores from metafrontier and technology gap ratio demonstrate that Sistan-va-Baluchestan has a higher technical operation among the selected provinces. Also, the results obtained from regional frontiers illustrate that the gap between the best fisherman and other fishermen is at its maximum in Bushehr while it is at the minimum in Hormozgan 
and Sistan-va-Baluchestan. The distribution pattern of technical efficiency estimates of fishing vessels from the metafrontier for the studied provinces is illustrated in Figure 2.

\section{Discussion}

Technical efficiency, its measurement and determining factors are of vital importance in production economic and decommissioning program. While technical efficiencies of fleets obtained according to a given frontier are comparable, this is not usually a valid case amongst fleets that operate under different technologies. Such problem occurs when the comparison of fleets from different provinces or regions of a country are involved (Battese et al., 2004). In fact, apart from the regional frontier analysis, the metafrontier analysis separates the technical efficiency into two groups: one due to the inefficiency relative to the subgroup, and one because of the technology gap between the subgroup and full sample. The empirical outcomes provide more policy suggestions (Battese et al., 2004). This study used the concept of the metafrontier production function to examine provincial differences in fish landed technologies of Iran.

\subsection{Inefficiency Relative to Subgroup}

Results of estimating regional frontier production function illustrated that mean technical efficiency for selected provinces ranges between 0.650 and 0.728 . This denotes that, there are opportunities for either rising total fish landing using the same inputs or lessening input for the current level of fish landing, or a combination of both by restricting the gap between the best fisherman and other fishermen. This opportunity is higher in Bushehr, while it is lower in Hormozgan and Sistan-va-Baluchestan. It is useful to compare the results found by this study for Hormozgan province with the results reported by Esmaeili (2006). However, this assessment should be made carefully because his technical efficiency scores were obtained using stochastic frontier analysis (SFA), while the results of this study were estimated using DEA. Esmaeili (2006) found the mean value of technical efficiency of a wooden vessel for Hormozgan province to be 0.85 , which is based on an expectation higher than the score obtained by this study. The studies in both fisheries and other sectors have usually found that DEA efficiency scores are correlated with, but lower than, those estimated using SFA. Technology gap values between Hormozgan fishery vessels and metatechnology were not reported in Esmaeili's study (2006) because he used only regional frontier analysis.

\subsection{Inefficiency Due to Technology Gap}

The value of technology gap ratio for the studied provinces varies between 0.624 and 0.763 . This ratio shows the maximum fish landing by a vessel from province $\mathrm{k}$ as a percent of the fish landing that is possible by metatechnology. Therefore, total fish landing can be increased significantly if fleets utilize the metatechnology or access to better natural endowment. The rank of studied provinces according to their technical operation is as follows: Sistan-va-Baluchestan, Hormozgan and Bushehr. The main explanations, beyond the fact that Sistan-va-Baluchestan has the highest technical operation in comparison with other provinces are access to more suitable vessels and especially, access to the deeper water in the Oman Sea and Indian Ocean to fish the big pelagic species, e.g. tuna. The combination of capture fisheries in selected provinces in 2006 is presented in Table 3. As shown in Table 3, more than 78 percent of total fish landing in Sistan-va-Baluchestan pertain to big pelagic species especially tuna fish (about 59\%), while the share of tuna fish species in the total fish landing of Hormozgan and Bushehr in this year is $19.08 \%$ and $13.27 \%$ respectively. Furthermore, about $55 \%$ of big pelagic species (about $70 \%$ of tuna fish) captured in 2006 on the Iranian southern fishery came from the Sistan-va-Baluchestan. Also, the share of demersal species which is under overexploitation in the total fish landing of Bushehr, Hormozgan and Sistan-va-Baluchestan is 49.57, 36.3 and 21.43\% respectively. Therefore, it seems Sistan-va-Baluchestan and to some extent Hormozgan, are where policy makers must execute their deep sea fisheries development policy and a buy-back scheme for reducing fleets to an appropriate size given the available fishing opportunities must be executed in Bushehr province. In this context, the findings of this study can help policy makers to determine the optimal reduction or increase fleet capacity.

\section{Acknowledgements}

This research was financially supported by grant No. 88-GR-AGR-4 from the Research Council of Shiraz University.

\section{References}

Battese, G. E., Rao, D. S. P., \& O'Donnell, C. J. (2004). A metafrontier production function for estimation of technical efficiencies and technology gaps for firms operating under different technologies. Journal of Productivity Analysis, 21, 91-103. http://dx.doi.org/10.1023/B:PROD.0000012454.06094.29 
Brooke, A., Kendrick, D., Meeraus, A., \& Raman, R. (1998). GAMS: A user's guide. GAMS Development Corporation. Washington, DC.

Eggert, H. (2001). Technical efficiency in the Swedish trawl fishery for Norway lobster. In Working Papers in Economics (Göteborg University, Department of Economics).

Esmaeili, A. (2006). Technical efficiency analysis for the Iranian fishery in the Persian Gulf. ICES Journal of Marine Science, 63, 1759-1764. http://dx.doi.org/10.1016/j.icesjms.2006.06.012

FAO. (1998). Report of the FAO technical working group on the management of fishing capacity. La Joya, USA.

FAO. http://www.fao.org/fi/oldsite/FCP/en/IRN/profile.htm

Garcia del Hoyo J. J., Castilla Espino, D., \& Jimenez Toribio, R. (2004). Determination of technical efficiency of fisheries by stochastic frontier models: A case on the Gulf of Cadiz (Spain). ICES Journal of Marine Science, 61, 416-421. http://dx.doi.org/10.1016/j.icesjms.2004.02.003

Hjalmarsson, L., Kumbhakar, S. C., \& Heshmati, A. (1996). DEA, DFA and SFA: A comparison. Journal of Productivity Analysis, 7, 303-327. http://dx.doi.org/10.1007/BF00157046

Huang, T.-H., \& Wang, M.-H. (2002). Comparison of economic efficiency estimation methods: Parametric and non-parametric techniques. Manchester School, 70, 682-709. http://dx.doi.org/10.1111/1467-9957.00320

Idda L., Madau F. A., \& Pulina, P. (2009). Capacity and economic efficiency in small-scale fisheries: Evidence from the Mediterranean Sea. Marine Policy, 33, 860-867. http://dx.doi.org/10.1016/j.marpol.2009.03.006

Kirkley J., Morrison Paul C., \& Squires, D. (2002). Capacity and capacity utilization in common-pool resource industries. Environmental and Resource Economics, 22, 71-97. http://dx.doi.org/10.1023/A:1015511232039

Kirkley J. E., \& Squires, D. (1999). Measuring capacity and capacity utilization in fisheries, In: Greboval, D. (Ed.) Managing fishing capacity: selected papers on underlying concepts and issues. FAO Fisheries Technical Paper, FAO, Rome, p. 386.

Lindebo E., Hoff A., \& Vestergaard, N. (2007). Revenue-based capacity utilisation measures and decomposition: The case of Danish North Sea trawlers. European Journal of Operational Research, 180, 215-227. http://dx.doi.org/10.1016/j.ejor.2006.03.050

Maravelias C. D., \& Tsitsika, E. V. (2008). Economic efficiency analysis and fleet capacity assessment in Mediterranean fisheries. Fisheries Research, 93, 85-91. http://dx.doi.org/10.1016/j.fishres.2008.02.013

O'Donnell, C.J., Rao, D.S.P. \& Battese, G.E. (2007). Metafrontier frameworks for the study of firm- level efficiencies and technology ratios. Empirical Economics, 34, 231-255.

Pascoe, S., Coglan, L., \& Mardle, S. (2001). Physical versus harvest-based measures of capacity: the case of the United Kingdom vessel capacity unit system. ICES Journal of Marine Science, 58, 1243-1252. http://dx.doi.org/10.1006/jmsc.2001.1093

Reid, C., Squires, D., Jeon, Y., Rodwell, L., \& Clarke, R. (2003). An analysis of fishing capacity in the western and central Pacific Ocean tuna fishery and management implications. Marine Policy, 27, 449-469. http://dx.doi.org/10.1016/S0308-597X(03)00065-4

Reinhard, S., Knox Lovell, C. A., \& Thijssen, G. J. (2000). Environmental efficiency with multiple environmentally detrimental variables; estimated with SFA and DEA. European Journal of Operational Research, 121, 287-303. http://dx.doi.org/10.1016/S0377-2217(99)00218-0

Sharma K. R., \& Leung, P. (1998). Technical efficiency of the longline fishery in Hawaii: An application of a stochastic production frontier. Marine Resource Economics, 13, 259-274.

Squires, D., Grafton, R. Q., Alam, M. F., \& Omar, I. H. (2003). Technical efficiency in the Malaysian gill net artisanal fishery. Environment and Development Economics, 8, 481-504. http://dx.doi.org/10.1017/S1355770X0300263

Tingley, D., Pascoe, S., \& Coglan, L. (2005). Factors affecting technical efficiency in fisheries: Stochastic production frontier versus data envelopment analysis approaches. Fisheries Research, 73, 363-376.

Vestergaard, N., Squires, D., \& Kirkley, J. (2003). Measuring capacity and capacity utilization in fisheries: the case of the Danish Gill-net fleet. Fisheries Research, 60, 357-368. http://dx.doi.org/10.1016/S0165-7836(02)00141-8 
Walden John B. \& Kirkley James E. (2000). Measuring Technical Efficiency and Capacity in Fisheries by Data Envelopment Analysis Using the General Algebraic Modeling System (GAMS): A Workbook, NOAA Technical Memorandum NMFS-NE-160.

Table 1. Number of fishermen and fishing vessels and amount of fish landed and fish landed per fisherman in southern coastal provinces of Iran

\begin{tabular}{ccccccc}
\hline & & \multicolumn{3}{c}{ Fishing vessels } & & Fish landed per \\
\cline { 3 - 5 } Province & Fishermen & Boats & Launch & Ship & Fish landed (Mt) & fisherman (Kg/person) \\
\hline Bushehr & 13209 & 1731 & 635 & 22 & 48113 & 3642.44 \\
Hormozgan & 27319 & 3075 & 873 & 35 & 120499 & 4410.81 \\
Khozestan & 37503 & 1552 & 722 & 0 & 45707 & 1218.76 \\
Sistan-va-Baluchestan & 23500 & 1707 & 1108 & 1 & 115353 & 4908.64 \\
Total & 101531 & 8065 & 3338 & 58 & 329571 & 3246.01 \\
\hline
\end{tabular}

Source: Iranian Fisheries Company

Table 2. Mean $( \pm \mathrm{SD})$ of technical efficiency based on regional frontier and metafrontier and technology gap ratio estimates for southern coastal provinces of Iran

\begin{tabular}{cccc}
\hline Province & Regional frontier & Metafrontier & Technology gap ratio \\
\hline Bushehr & $0.650 \pm 0.156$ & $0.408 \pm 0.077$ & $0.641 \pm 0.104$ \\
Hormozgan & $0.728 \pm 0.110$ & $0.479 \pm 0.069$ & $0.665 \pm 0.089$ \\
Sistan-va-Baluchestan & $0.727 \pm 0.119$ & $0.542 \pm 0.064$ & $0.763 \pm 0.108$ \\
\hline
\end{tabular}

Table 3. Amount (Mt) and percent of type of captured fish in 2007 in selected southern coastal provinces of Iran

\begin{tabular}{ccccc}
\hline Fish type & Bushehr & Hormozgan & Sistan-va-Baluchestan & Total \\
\hline Big pelagic & $23419(48.67)$ & $52445(43.52)$ & $90524(78.54)$ & $166388(58.62)$ \\
Tuna fish & $6384(13.27)$ & $22997(19.08)$ & $68204(59.18)$ & $97585(34.38)$ \\
Others & $17035(35.41)$ & $29448(24.44)$ & $22320(19.37)$ & $68803(24.38)$ \\
Small pelagic & $843(1.75)$ & $24634(20.44)$ & $24(0.00)$ & $25501(8.98)$ \\
Demersal & $23581(49.57)$ & $43420(36.03)$ & $24704(21.43)$ & $91705(32.31)$ \\
Total & $48113(100)$ & $120499(100)$ & $116252(100)$ & $283864(100)$ \\
\hline
\end{tabular}

Source: Iranian Fisheries Company

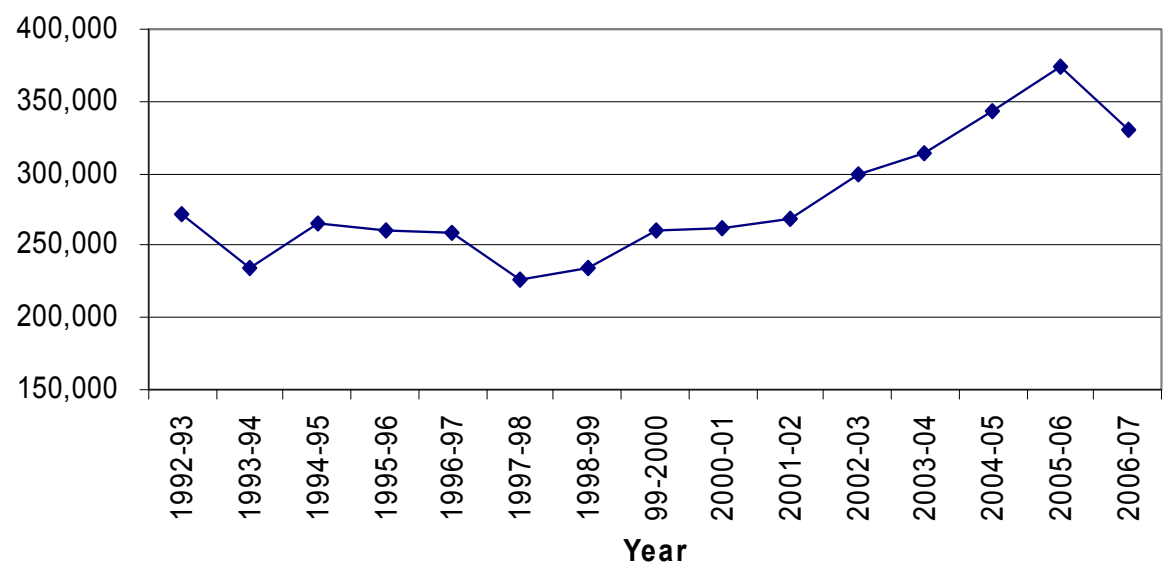

Figure 1. Total fish landed in southern Iran (1000 tons)

Source: Iranian Fisheries Company 


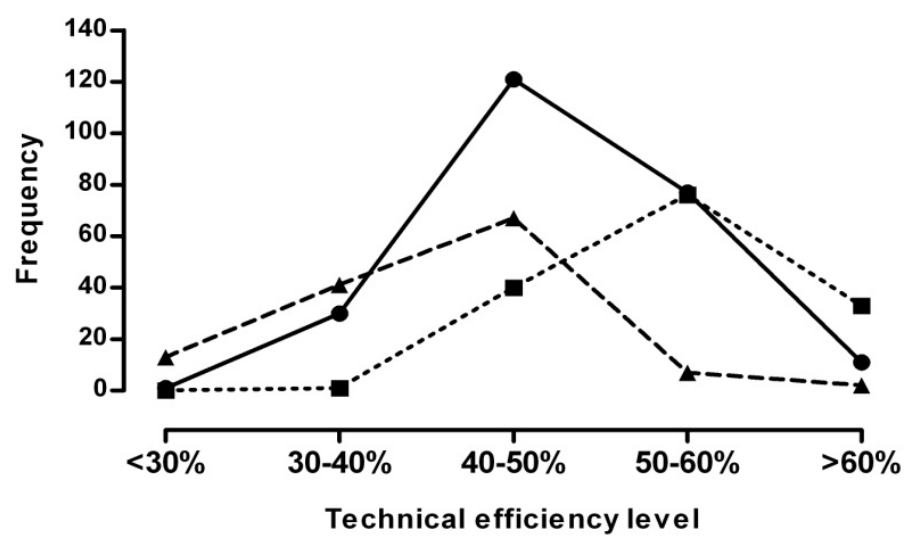

Figure 2. Distribution pattern of technical efficiency estimates of fishing vessels in southern coastal provinces of Iran; Hormozgan $(-\bullet-)$, Sistan-va-Baluchestan $(-\mathbf{-}-)$, and Bushehr $(-\mathbf{\Lambda}-)$ 